of asthma, little is known about the specific relationship between asthma, occupational exposures and health-related quality of life.

Methods Adults aged over 55 years in the Sheffield area of the UK were randomly mailed a self-completed questionnaire (including questions on respiratory symptoms and physician-diagnosed disease, smoking and occupational history); responders were invited to perform lung function ( $\mathrm{FEV}_{1}$ and $\left.\mathrm{FVC}\right)$, and to complete the EQ$5 \mathrm{D}-3 \mathrm{~L}$ instrument. A measure of socioeconomic deprivation (SED) derived from postal code data was also included.

Results 623 individuals provided data as detailed above. 57\% were male, $62 \%$ were "ever smokers", $13 \%$ had an exclusive diagnosis of asthma (without any other respiratory disease) and 62\% reported occupational exposure to vapours, gases, dusts or fumes (VGDF). A linear regression analysis was performed using the EQ-5D summary index score as the dependent variable and reported doctor diagnosed asthma, age, gender, percentage predicted $\mathrm{FEV}_{1}$ (PPFEV), smoking history and prior history of VGDF exposure as independent variables. SED $(p<0.001)$, Age $(p<0.001)$, gender $(p<0.001)$ and VGDF exposure $(p<0.001)$ were all independently associated with a lower quality of life. Asthma $(p=0.394)$ and smoking $(p=0.541)$ were not. Discussion These data do not support a link between self reported doctor diagnosed asthma and a reduction in quality of life in this population, after correcting for the effects of other relevant factors, although do support a link between occupational exposure to VGDF and a reduced health-related quality of life.

\section{S136 PRE- AND POST-SPECIFIC INHALATIONAL CHALLENGE MEASUREMENTS OF FRACTIONAL EXHALED NITRIC OXIDE (FENO) IN THE DIAGNOSIS OF OCCUPATIONAL ASTHMA}

doi:10.1136/thoraxjnl-2012-202678.141

GI Walters, VC Moore, PS Burge. Birmingham Heartlands Occupational Lung Disease Unit, Birmingham, UK

Introduction The interpretation of Specific Inhalation Challenge (SIC) can be equivocal, particularly for late asthmatic reactions. It has been suggested that increases in $\mathrm{FE}_{\mathrm{NO}}$ 24-hours post-challenge might help separate positive from negative challenges.

Methods We reviewed all positive and equivocal SIC tests with occupational agents between March 2008 and June 2012 from our tertiary referral centre. $\mathrm{FE}_{\mathrm{NO}}$ was measured pre- and 24-hours post control and active challenges using a Niox Mino handheld machine at $50 \mathrm{ml} / \mathrm{sec}$, compliant with ERS/ATS recommendations. Post-challenge changes $>20 \%$ for $\mathrm{FE}_{\mathrm{NO}}>50 \mathrm{ppb}$, or $>10 \mathrm{ppb}$ for $<50 \mathrm{ppb}$, were counted as per ATS guidelines for a clinically significant change (1).

Results 24 patients had complete data related to control and active challenges, which were positive in 15 and equivocal in 9 cases. 13/24 patients had raised pre-control challenge $\mathrm{FE}_{\mathrm{NO}}($ mean=31.3) after adjusting for smoking and inhaled corticosteroid use. Increases in $\mathrm{FE}_{\mathrm{NO}}$ more than the minimum clinically relevant difference, were seen after 13/24 control challenges: including 6/7 exposures to cleaning agents or hand gels and 2/6 unused metalworking fluids. 5/24 patients had a clinically significant increase in $\mathrm{FE}_{\mathrm{NO}}$ after positive or equivocal challenges: including $1 / 4$ challenges with isocyanates, $1 / 6$ cleaning agents or hand gels, and $2 / 3$ with used metalworking fluids. There was no statistically significant difference in mean percentage change in $\mathrm{FE}_{\mathrm{NO}}$ between control and active challenges.

Conclusions The previously defined minimum clinically relevant difference for $\mathrm{FE}_{\mathrm{NO}}$ was seen as commonly following control as active challenges. Measuring changes in $\mathrm{FE}_{\mathrm{NO}}$ pre- and 24-hours post challenge to the diverse range of low molecular weight agents tested did not provide useful additional information for interpreting SIC responses.

Reference

1. Dweik RA et al. An Official ATS Clinical Practise Guideline: Interpretation of Exhaled Nitric Oxide Levels $\left(\mathrm{FE}_{\mathrm{NO}}\right.$ ) for Clinical Applications. Am J Respir Crit Care Med 2011; 184:602-15.

\section{Treating asthma}

\section{P1 OMALIZUMAB IN PAEDIATRIC ASTHMA: IMPORTANCE OF MULTI-DISCIPLINARY ASSESSMENT TO IDENTIFY ELIGIBLE PATIENTS}

doi:10.1136/thoraxjnl-2012-202678.142

S Rao, L Barrett, S Frost. Birmingham Children's Hospital NHS Trust, Birmingham, UK

Omalizumab is effective treatment for patients with severe asthma. It is reserved for patients with truly severe disease as it is expensive and associated with significant treatment burden. Identifying this small number of patients in problematic severe asthma (PSA) group is challenging. We evaluated the impact of multi-disciplinary severe asthma (SA) protocol on identifying those with severe disease and on potential use of omalizumab.

After initial clinic visit, 19 patients aged between 6-15yrs with PSA underwent specialist nurse led SA protocol which included: assessment of clinical status, lung function, atopy, inhaler technique, asthma control test (ACT), quality of life ( $\mathrm{QoL}$ ); home visit for further assessment of environment, adherence and psychosocial comorbidities; school contact to address impact on education.

Before SA protocol, 17/19 patients met criteria for use of omalizumab. After SA protocol, only $6(35 \%)$ were eligible as modifiable factors were identified in $11(65 \%)$. They included poor adherence, ongoing allergen exposure and psychological issues. 5/6 patients received omalizumab and $4(80 \%)$ improved. Of other 11 patients, clinical status improved in $6(55 \%)$, unchanged but stable in $4(36 \%)$, worsened in $1(9 \%)$ after assessment.

SA protocol identified modifiable factors in significant proportion of PSA children limiting omalizumab use to those with truly severe disease. Home visit assessment is essential to identify these factors which would otherwise be unrecognised. We hypothesise that proper recognition and management of these factors might not only ensure appropriate use of omalizumab but also improve its effectiveness

\section{P2 EVALUATION OF SWITCHING THERAPY FROM FIXED-DOSE COMBINATION INHALED CORTICOSTEROID/LONG-ACTING BETA2AGONIST TO BECLOMETASONE DIPROPIONATE/ FORMOTEROL (FOSTAIR 100/6®)}

doi:10.1136/thoraxjnl-2012-202678.143

${ }^{1} \mathrm{~T}$ Harris, ${ }^{2} \mathrm{~S}$ Small, ${ }^{3} \mathrm{D}$ Price, ${ }^{4} \mathrm{~J}$ Haughney, ${ }^{5} \mathrm{D}$ Ryan, ${ }^{6} \mathrm{~K}$ Gruffydd-Jones, ${ }^{7} \mathrm{M}$ Ali, ${ }^{7} \mathrm{~S}$ Musgrave, ${ }^{7} \mathrm{~J}$ Brockman, ${ }^{8} \mathrm{~F}$ Lavorini, ${ }^{9} \mathrm{~A}$ Papi. ${ }^{1}$ Chiesi UK, United Kingdom; ${ }^{2} \mathrm{NHS}$ Grampain, United Kingdom; 'University of Aberdeen, Aberdeen, United Kingdom; ${ }^{4}$ International Primary Care Respiratory Group, United Kingdom; ${ }^{5}$ Medical School Teviot Place, Edinburgh, United Kingdom; ${ }^{6}$ Royal College of General Practitioners, United Kingdom; ${ }^{7}$ Research in Real Life, Cambridge, United Kingdom; ${ }^{8}$ University of Florence, Florence, Italy; ${ }^{9}$ University of Ferrara, Ferrera, Italy

Introduction and Objectives Asthma therapy reviews aim to minimise side-effects and achieve cost-effective asthma control. We set out to examine the impact of switching from a fixed dose combination therapy inhaled corticosteroid/long-acting $\beta 2$ agonist (FDC ICS/LABA) therapy via dry power inhaler (DPI) or metereddose inhaler (MDI) to beclometasone dipropionate/formoterol (BDP/FOR) via MDI at the same or reduced dose of ICS in stable patients.

Methods We utilised the UK's Optimum Patient Care Research Database to identify suitable primary care patients (aged 18-80 years) with asthma (diagnostic code and/or $\geq 2$ asthma prescriptions in the last year) who were changed from FDC ICS/LABA to a prescription of BDP/FOR MDI at the same or lower BDP-equivalent ICS daily dose following a review of their existing ICS/LABA therapy. The number of exacerbations was measured as an outcome, 